\title{
DISCUTINDO A METODOLOGIA DO ENSINO DE CIÊNCIAS E MATEMÁTICA: críticas e possibilidades à prática docente
}

\author{
Discussion of Science and Math Teaching Methods: criticism and possibilities \\ in teaching practices
}

\section{RESUMO}

Discuto a metodologia de ensino de professores de Ciências e Matemática na educação básica brasileira. Evidencio críticas referentes à prática docente desenvolvida nessas áreas de conhecimento ao longo dos níveis de escolarização básica: Educação Infantil, Ensino Fundamental e Médio. Destaco ainda a opção por projetos didáticos interdisciplinares como possibilidade metodológica instrumentalizadora de uma prática resignificada e reflexiva nesses âmbitos. Postulo, nesse sentido, que os problemas apontados possam ser enfrentados, por meio de opções teóricas compartilhadas e postura metodológica investigativa, incentivadas pelas instâncias de formação de professores, através do investimento no paradigma do professor - pesquisador da própria prática, maximizando as perspectivas de tal tendência no âmbito da formação inicial e contínua de professores, uma vez que seus pressupostos figuram como elementos catalisadores das opções de mudanças metodológicas almejadas para educação em ciências e matemática do País.

Palavras-chave: Formação docente, Educação em ciências e matemática, Metodologia de ensino, Investigação da própria prática.

\section{ABSTRACT}

This paper presents a discussion of practices among Science and Math teachers in Brazilian Basic Education. Analysis focuses on criticism over teaching practices throughout Basic Education which includes Children, Primary and Medium levels. Discussion highlights the interdisciplinary and educational projects as the most chosen tool for reflective practices. Most educational problems must be solved by the use of shared theoretical choices and investigative methodological approach. Such choices ought to be made during teachers' continuing trainning based on a researcher-teacher action as it provides ways for methodological changes in Sciences and Math Education in the Country.

Key words: Teacher trainning, Science and Math Education, Teaching Methods, Research.

Elizabeth Cardoso Gerhardt Manfredo ${ }^{1}$

\section{INTRODUÇÃO}

Meu propósito neste texto é discutir a prática e a formação de professores de Ciências e Matemática, assinalando críticas referentes aos problemas que vêm caracterizando a metodologia de ensino nesses campos. Assim como, indico possibilidades formativometodológicas, que podem re-significar tal prática, tendo em vista uma qualidade educativa para os sujeitos que freqüentam os espaços da educação básica brasileira.

Para tais intenções, inicialmente centro meu olhar na prática docente desenvolvida ao longo da escolarização básica do País, a saber Educação Infantil, Ensino Fundamental e Ensino Médio. Aponto, nesse momento, um quadro de problemas que caracterizam cada uma das duas áreas no que tange, as situações didáticas durante o processo de ensino e de aprendizagem, em cada nível, e também evidencio problemas formativos oriundos dos cursos de qualificação profissional dos professores desses campos, tanto inicial, quanto em serviço.

Na segunda parte do texto, organizo uma discussão acerca de propostas teórico- metodológicas a partir das quais professores de Ciências e de Matemática poderão inovar reflexivamente suas metodologias de ensino e, assim, contribuir com a alfabetização matemática, científica e tecnológica da população. Tais propostas têm como elemento central projetos didáticos interdisciplinares para o ensino de Ciências e Matemáticas, a partir dos quais o professor, em ambas as áreas, busca a interdisciplinaridade e a contextualização, podendo exercitar as tendências metodológicas correlatas às áreas, tais como História da Ciência/Matemática; modelagem matemática, utilização de jogos, a proposta CTS (Ciência Tecnologia \& Sociedade) dentre outras.

Como elemento fundamental da discussão anterior, na seção final, focalizo o papel das instâncias de formação de professores a quem cabe ampliar a discussão e assumir em seus currículos a perspectiva da formação pela investigação da própria prática (ALARCÃO, 2003, PONTE, 2002 b; ZEICHNER, 1992; 1993; GONÇALVES, 2000, 2003) antevendo um desenvolvimento profissional em novas bases aos professores em formação.

\footnotetext{
1 Mestre em Educação em Ciências e Matemática, Professora de Metodologia e Prática de Ensino da Universidade Federal do Pará - Campus de Marabá.

2 Sistema de Avaliaçào da Educação Básica.
}

A M A Z Ô N I A - Revistá de Educafäo em Ciencias e Matemáticas, v. 1 - n. 1 -juL/dez. 2004, v. 1 - n. 2 - jan.jun. 2005 


\section{OENSINO DE CIÊNCIASEMATEMÁTICAAO LONGODA EDUCAÇÃO BÁSICA: CARACTERÍSTICASE ALGUMAS CRÍTICAS}

Para quê, o quê e como se ensina e se aprende nas aulas de Ciências e Matemática na educação básica brasileira? Quando tais questões são postas, há uma profusão de idéias que revelam uma lamentável constatação: Há uma baixa qualidade educativa do aluno nesses componentes curriculares nos vários niveis da escolarização em nosso País (SILVA, 2002; CARVALHO, 1994; DELIZOICOV \& ANGOTTI, 1998; ARAÚJO \& LUZIO, 2004; CUNHA \& CICILLINI, 1995), sendo recorrentemente apontado em mecanismos de avaliação do Governo. "De acordo com o Saeb ${ }^{2}$...o desenvolvimento de habilidades básicas em matemática vem se revelando insuficiente..."(ARAÚJO \& LUZIO, 1998,p.01), com alunos apresentando desempenhos que revelam graus de 'analfabetismo matemático', algo que se estende ao ensino de ciências naturais, que também se apresenta como desmotivador e inócuo, podando, pela ausência, o espirito da descoberta inerente a cada indivíduo. Mas, por que isso ocorre? Os problemas envolvendo tais interrogações são complexos, quando se focaliza a Educação Infantil; o Ensino Fundamental e o Ensino Médio. Nestes, a proposta metodológica (ou falta dela) merece ser apontada e discutida para que sejam observados caminhos de reorientação pertinentes a cada realidade.

A apropriação de conhecimentos científicos e matemáticos ${ }^{3}$ é fundamental para que o indivíduo exerça adequadamente sua cidadania e conviva de modo satisfatório em meio às mudanças vividas no contexto societário, local e planetário. Nos diversos espaços da vida fisica e social, a Matemática está presente, sendo necessária para a utilização de códigos, notações, relações e esquemas explicativos, demonstrações teóricas etc. Da mesma forma, os conhecimentos relacionados às ciências naturais como habilidade de investigar, observar, levantar hipóteses, discutir, propor modelos explicativos, enfim compreender o mundo circundante e suas transformações, fazendo uso e convivendo com incontáveis produtos científicos e tecnológicos, são demandados e constituem-se como essenciais para que o indivíduo articule vários aspectos interligados à ciência, agindo de modo crítico e consciente de seu importante papel nas relações bio-sócio-econômicas.

Para que a educação científica, matemática e tecnológica aqui defendida eleve a qualidade educativa dos alunos há necessidade de uma metodologia de ensino que de fato acompanhe o processo de aprendizagem, valorizando esquemas conceituais autônomos, espontâneos, propondo experiências significativas em que o objeto de conhecimento seja construído pelo aluno e não imposto mecanicamente, por meio de técnicas algorítmicas e superformalizadas, ou através de uma visão monolítica, absoluta e fragmentária de fatos e fenômenos naturais e sociais. Enfim, uma prática que permita o alcance do objetivo de alfabetizar matemática e cientificamente as populações de nossas escolas.

Apesar da existência de estudos ligados a várias áreas como psicologia da aprendizagem, epistemologia, ensino de ciências, e educação matemática, e desses apontarem para a perspectiva acima assinalada, incluindo, nos parâmetros e diretrizes curriculares, objetivos, conteúdos e sugestões didáticas e avaliativas consoante a tais propostas, a realidade das aulas de ciências e matemáticas, ao longo dos níveis e modalidades de ensino, não refletem os avanços alcançados nos estudos e materiais citados.

\section{AMETODOLOGIADE ENSINODE CIÊNCIASE MATEMÁTICANASSÉRIESINICIAIS}

Para o primeiro nível da educação básica e parte do segundo, ou seja, da Educação Infantil a $4^{\mathrm{a}}$ série, o que se vê, na maioria das práticas docentes é algo diverso do que se advoga nos cursos de formação, na literatura sobre o assunto e orientações dos RCNEI, e PCNS ${ }^{4}$.

Embora a qualidade conclamada nesses espaços e nessas orientações respondam satisfatoriamente aos objetivos defendidos, a real democratização dos saberes referentes às duas áreas - uma formação científica estimulante do desenvolvimento de postura reflexiva, crítica, questionadora e investigativa diante dos fenômenos naturais e sociais; e ainda catalisadora de capacidades intelectuais no que tange à estruturação do pensamento, agilidade do raciocínio dedutivo importante à resolução de problemas e a outras atividades da vida social cotidiana ${ }^{5}$ - não ocorre. Observa-se uma prática inócua, em que pouca ou nenhuma atenção é dispensada a esses componentes, ou seja, os processos significativos apontados por Ausubel (SCHNETZLER, 1992) estão ausentes nas aulas de ciências e matemática ao longo da escolarização básica ${ }^{6}$.

Partindo da Educação Infantil, sabemos que historicamente a educação pré-escolar vem preocupandose mais com a prontidão do aluno, um modo de aprender mas rápido a leitura e escrita, do que, propriamente, o desenvolvimento de aspectos cognitivos e científicos, incluídos aí conceitos matemáticos e científicos. $\mathrm{O}$ professor torna sua aula repleta de exercicios motores e cópias mecanizadas de letras, números e palavras, preterindo atividades investigativas de vários fenômenos naturais instigadores da curiosidade inata do individuo, bem como de atividades que possibilitem a construção do

\footnotetext{
${ }^{3}$ A Matemática, embora integre o grupo das ciências, receberá tratamento distinto em relação às Ciências Físicas, Químicas, Biológicas e Geológicas.

' Referencial Curricular Nacional para Educação Infantil (1998); Parâmetros Curriculares Nacionais ( $1^{\mathrm{a}}$ a 4 e $5^{\mathrm{a}}$ a $8^{\mathrm{a}}$ séries)

5 Conforme também defende o texto dos Parâmetros Curriculares Nacionais de Ciências Naturais e Matemática, respectivamente (Volumes 3 e 4).

'A aprendizagem significativa, segundo Ausubel, ocorre quando novos significados são adquirịdos e atribuídos pelo aprendiz, através de um processo de interação (implicando subsunção ou ancoragem subsequente) de novas idéias com conceitos ou proposições relevantes já existentes na sua estrutura cognitiva (construto hipotético que reflete a organização de idéias na mente de um individuo). $O$ contrário do que ocorre na aprendizagem mecânica que se caracteriza por uma organização de informações com pouca ou nenhum a interação com conceitos ou proposições relevantes existentes na estrutura cognitiva do aprendiz (SCHNETZLER, 1992, P. 17).
} 
conceito de número, que de acordo com estudos na área não pode ser ensinado (KAMMI, 1991), mas sim construído por meio de atividades planejadas apropriadamente. São advindas desse contexto, causas das várias dificuldades de relacionar, classificar, inferir, abstrair, compreender e resolver problemas, bastante evidenciadas em avaliações de desempenho de alunos. Segundo Araújo \& Luzio (2004) alunos que não desenvolvem certas competências, construindo e reconstruindo habilidades de média e alta complexidade, prosseguirão a trajetória escolar acumulando sérios déficits.

Ao aprender a ler (até antes disso), o aluno é promovido para cursar as quatro primeiras séries do Ensino Fundamental. Nelas, os conhecimento matemáticos e científicos são agrupados em disciplinas a partir das quais o professor deverá iniciar o aprofundamento progressivo e necessário aos demais niveis do Fundamental e do Ensino Médio.

Nas séries iniciais quem organiza as ocorrências das aulas de determinada disciplina é o coordenador ou, na maioria dos casos, o professor. Diz "hoje é aula de Matemática, amanhã será de Ciências". Nesses momentos o que se observa, por exemplo, nas de matemática, é a tentativa de ensinar a todo custo as quatro operações (Adição, Subtração, Multiplicação e Divisão), de modo que o aluno mostre seu desempenho (aprendizado) efetuando-as de acordo com os algoritmos repassados e explicados pelo professor, com base no livro didático. Não é aceitável pelo professor formas alternativas de resolução das operações ou outros conteúdos, posto que retirou do livro, entendeu e explicou, apenas aquela que, agora, exige. Não é dada atenção nenhuma aos "erros", muitas vezes absurdos, cometidos pelos alunos ao buscar resolver por meio de suas próprias hipóteses e estratégias (CARRAHER et all, 1995) uma vez que o professor não as valoriza ou compreende. Enfim, a matemática é transmitida de modo precocemente formalizado e o aluno que consegue seguir o "modelo", ou entende a lógica seguida pelo livro ou pela explicação do professor, está aprovado à série seguinte.

Nesse caso, embora, de modo questionável, o aluno ainda tem contato com parcos conhecimentos matemáticos. Porém, em muitos casos, a própria dificuldade docente em relação ao conteúdo matemático, como fruto de uma educação que agora reproduz, é que determina o nivel de freqüência das aulas e aprofundamento de conteúdos. Se a facilidade do professor reside em adição, e subtração é certo que será isso que ensinará. Por outro lado, se sua dificuldade é efetuar operações fracionárias é também certo que isso não será aprofundado", pois se o professor, durante a sua formação, não vivenciar a experiência de sentir-se capaz de entender Matemática e de construir algum conhecimento matemático, dificilmente aceitará tal capacidade em seus alunos." (CARVALHO, 1994, p. 17). Em trabalho sobre concepções e práticas docentes de professores de Matemática nas séries iniciais (MANFREDO, 2004) discuto algumas questões referentes aos implicadores de questões como essas ao ensino de matemática nas séries iniciais.

Em se tratando do ensino de Ciências, o problema não é menos complexo e preocupante. Entendida e ensinada como uma disciplina "decorativa" Ciências na
Educação Infantil e séries iniciais é ensinada mediante fatos e fenômenos que são informados pelos livros didáticos, como uma verdade absoluta e inquestionável, veiculando uma idéia mitificada de que quem faz ciência são os super dotados ou loucos de laboratório; sendo o cientista caracterizado como uma figura excêntrica, ou mesmo um "gênio" (DELIZOICOV \& ANGOTTI, 1998). A ciência que está na vida de cada aluno não é valorizada pelo professor, muito menos seus modelos explicativos acerca do mundo que o rodeia. Nesse sentido, o que se aprende são as idéias trazidas nos livros didáticos que serâo cobradas, tal e qual, são informadas, sem nenhum tipo de questionamento. Nesse sentido o professor assume papel "ativo no processo, já que fala $90 \%$ do tempo em sala de aula tentando 'passar' ou 'cobrir' o conteúdo para alunos silenciosos, os quais devem passivamente internalizá-lo e reproduzi-lo em termos verbatim nas avaliações (SCHNETZLER. 1992, p. 17). Quando ocorre, a experimentação, esta reduz-se a seguir um roteiro dado pelo livro ou pelo professor que deverá conduzi-lo para fins de comprovação, tal como a experiência sugere, buscando a verdade cientifica (LABURU, 1998). Nem o professor tem autonomia para modificar qualquer procedimento, nem o aluno a teria,visto que; em função do modelo docente, sente-se também inseguro em questionar ou refutar as informações recebidas e a observação do experimento, ainda que observe alguma contradição, ou seja, que seu modelo espontâneo colida com a explicação da Ciência.

Em função do cenário exposto, as aulas de Ciências e Matemática impossibilitam um avanço no conhecimento ou uma ampliação conceitual por parte do aluno, o que demonstra a necessidade de se pensar formas de alterar tal problemática que também é extensiva às séries posteriores.

\section{AMETODOLOGIADE ENSINODE CIÊNCIAS E MATEMÁTICADE $5^{a}$ A $8^{a}$ SÉRIES}

No segmento $5 \mathrm{a}$ a $8 \mathrm{a}$, os problemas permanecem ou se intensificam. Embora se busque maior ênfase nas áreas, as aulas continuam mecanizadas e sob a égide do livro didático, que se torna o único veículo de informação do professor, demonstrando total ausência de proposta teórico-metodológica. $O$ professor concentra sua ação no repasse descontextualizado de conteúdos, entendendoos como prontos e acabados. Em Matemática, por exemplo, intensificam a prática de mostrar exemplos no quadro, definindo termos e processos, com o intuito de que os alunos sejam capazes de resolver, posteriormente, uma lista de exercícios padronizados, centrando o ensino em treino de técnicas e demonstrações algorítmicas, que longe de democratizar, excluem o aluno do conhecimento matemático. (ROCHA, 2001; NAMERI, 1995; SILVA, 2002; MEDEIROS, 1989, THOMAZ, 1994).

Nas aulas de Ciências para o mesmo nível, o quadro não difere substancialmente do exposto até aqui, uma vez que se ensina Ciências, por meio de definições, informações de descobertas de fatos científicos correlatos, que determinam e direcionam o pensamento para um método único, universal e inquestionável. A prática da experimentação, como frisei, para a etapa anterior, reduz o 
processo a meras aplicações de procedimentos, com demonstrações de constatação e comprovação das leis formuladas por outrem (MOURA \& VALE, 2003).

Além disso, as Ciências (envolvendo Física, Biologia, Química e Geociências) são transmitidas como algo distante e inatingivel, não possibilitando ao aluno a articulação com outros conhecimentos de áreas científicas diferentes. Soma-se a isso o fato de que não há preocupação do professor em possibilitar discussões sobre as finalidades de cada uma dessas Ciências, menos ainda com a necessária e já mencionada relação ciência, tecnologia e sociedade, havendo uma pseudoaprendizagem da postura científica, condição relevante para o exercício da cidadania.

Moura \& Vale ( 2003, p. 128) denunciam que "A compreensão da relação entre o desenvolvimento científico e o econômico-social e a percepção das dimensões histórica, social e ética do processo de produção da ciência e da tecnologia estão ausentes da sala de aula" de $5^{\mathrm{a}}$ a $8^{\mathrm{a}}$ séries. Isso é grave, posto que ao se caminhar com essa metodologia da transmissão acrítica de conteúdos estanques e apartados do contexto da vida dos alunos, elimina-se a dimensão investigativa e este torna-se passsivo e reprodutor de um sistema cristalizado. Observa-se, portanto que "Este modelo de ensino desfavorece qualquer tentativa de formar um ser crítico, pensante e atuante na sociedade (MOURA \& VALE, 2003).

\section{AMETODOLOGIA DOENSINODEQUIMICA, FÍSICA, BIOLOGIA E MATEMÁTICANO ENSINO MÉDIO}

Chegando ao Ensino Médio o aluno, que vem experimentando as aulas de ciências e as de Matemática, nos termos aqui destacados, encontra sérias dificuldades em compreender os fenômenos e relações teóricas das áreas de Química, Física, Biologia e Matemática. São vários problemas que vem se arrastando. O aluno, por um lado, não vê importância em determinados conteúdos, não atribuindo-lhes significado e nenhuma aplicabilidade, por outro, o professor insiste nos conteúdos factuais e destituídos de sentido real, o que corrobora a alienação a que ambos são submetidos (ROCHA, 2001). Nessa etapa da escolarização, em que é exigido desse aluno habilidades de lidar de modo mais complexo, com modelos e sistemas explicativos, utilizando de determinado instrumental teóricometodológico das várias áreas, devendo compreender as relações existentes entre Ciência, Tecnologia e Sociedade para o exercicio pleno de sua cidadania, no contexto do mundo social e do trabalho, o foco prevê a contextualização e a interdisciplinaridade como conceitos aplicáveis e de impactos desejáveis a um novo perfil de cidadão que entenda o mundo em relação e não fragmentado, o que exige ainda mais a articulação entre as áreas.

Lamentavelmente isso não ocorre ${ }^{7}$. A prática no
Ensino Médio, conforme mencionei, não atende aos interesses de uma formação científica e matemática apropriadas às atuais demandas do mundo físico e social. Destaco salas com jovens em idade favorável a profícuas discussões e posicionamentos críticos e propositivos sobre o homem e seu papel na sociedade, que, infelizmente, não realizam experiências argumentativas e reflexivas, nesse sentido. Longe disso se observam aulas em que conteúdos científicos e matemáticos são mais uma vez trabalhados como verdades imutáveis e totalmente desvinculados de questões sociais mais amplas e de uma formação para atitudes e valores éticos, socialmente desejáveis. Algo que deveria ser desenvolvido como meta consciente desde o início da escolarização desse indivíduo.

Abaixo resumo algumas das dificuldades que professores de Biologia do Ensino Médio de Bauru, apresentam no desenvolvimento de sua ação didática, de acordo com estudo de Teixeira \& Vale (2003, p.35). Tais dificuldades acredito que possam estar relacionadas aos problemas enfrentados pelos demais professores, em cada nível de ensino, no que tange implicadores de sua ação teórico-metodológica, algo que resume a metodologia de ensino até aqui explorada. (a) $O$ enfoque dos conteúdos limita-se à esfera estritamente biológica; (b) a reflexão sobre inovações em objetivos e práticas de contextualização ainda é incipiente; (c) número reduzido de aulas na semana; (d) as metodologias utilizadas $e$ demais processos pedagógicos são excessivamente tradicionais e resistentes às mudanças; (e) Inovações tecnológicas e outros assuntos ligados a CTS são ainda objeto de pouca atenção docente; (f) desvinculação dos conteúdos programáticos do contexto da realidade social (relação teoria e prática); ( $g$ ) O salário dos docentes e demais profissionais envolvidos na área é baixo, o que desmotiva o aluno que forma-se professor; entre outras

Embora o estudo trate de três categorias de dificuldades, as relacionadas: à prática de Ensino de Biologia (1); à formação dos professores (2); e à crise na educação brasileira (3), optei em destacar problemas referentes à primeira, reconhecendo, obviamente, as imbricações entre as três.

Dizendo de outro modo, ou acrescentando novas questões àquelas postas pelos autores destacados, faço referência a alguns elementos que reforçam a situação a que são submetidos os alunos do ciclo básico, uma vez que interferem na metodologia de ensino empregada nas aulas de Ciências e Matemática.

Um primeiro diz respeito à precária qualidade formativa de professores, notadamente dos atuantes nas séries iniciais e educação infantil, que estiveram ou ainda permanecem na situação de leigos. A atual LDB, garante a formação mínima em nível de profissionalização na modalidade média normal. Acredito que isso pode trazer um retrocesso, desqualificando a formação necessária para esse âmbito, uma vez que, para

\footnotetext{
7 Por razões várias que vão desde a carência de professores, principalmente de Física e Quimica, o que demonstra um fenômeno de desinteresse e descrédito pelo magistério em função do quadro de desvalorização histórica, passando por aspectos referentes à organização do espaço e do tempo escolar, indo até à prática docente nas áreas que recebe várias influências, dentre as quais destaco as instâncias formadoras, o que se estende as demais professores nos outros niveis já mencionados.
} 
os demais níveis, exigi-se a formação universitária, e, principalmente, por entender que a complexidade dos fenômenos educativos, envolvendo o processo de ensino e de aprendizagem de conceitos e extensivo a todos os níveis e modalidades do ensino, o que justifica formação adequada, com tempo e qualidade nas experiências, e tendo a pesquisa como princípio formativo. Discutindo a formação profissional do professor de ciências Cunha \& Cecillini (1995, p. 213) assinalam a importância de uma reflexão sobre a formação de $1^{\mathrm{a}}$ a $4^{\mathrm{a}}$ dizendo:

Ensinar crianças menores exige um conhecimento profundo de todo o conteúdo por ser desenvolvido com essas crianças. No caso de ciências, na realidade um conteúdo interdisciplinar...o curso para o magistério apenas de nível médio não é suficiente, com seu quadro curricular, para a formação necessária ao professor de à a $4^{\mathrm{a}}$ séries.

Outra questão que se soma a anterior, diz respeito à permanência histórica da cultura da disciplinaridade, ou uma hiperdisciplinaridade nos currículos escolares, não sendo abandonada em termos epistemológicos e metodológicos por gestores e professores, o que concorre sobremaneira para o impedimento na articulação entre as áreas e disciplinas, algo cultivado no Ensino Fundamental $5^{\mathrm{a}}$ a $8^{\mathrm{a}} \mathrm{e}$, sendo ainda reiterado no Ensino Médio.

Um outro impulsionador do elemento mencionado anteriormente, que, por sua vez, o gera, num ciclo vicioso, e que se liga aos aspectos formativos destacados, é o modelo de formação a que são (eram?) submetidos os professores para essas realidades. Um modelo em que a relação teoria e prática é vertiginosamente dicotomizado, sendo dessa forma, um impeditivo para a vivência profissional e a construção da identidade profissional de professor, conforme a literatura (PIMENTA, 1997; GONÇALVES, 2000; PONTE, 2002; MANFREDO, 2004, PAIVA, 2002) destaca.

Cunha \& Cecillini (1995) referindo-se à qualidade formativa atinente aos professores oriundos das universidades (os licenciados plenos), afirmam haver sérios problemas nesse sentido, dentre os quais destacam: $a$ dicotomia bacharelado licenciatura; reduzida carga horária de disciplinas ligadas ao ensino e sua reflexão, como Filosofia, História da educação e da ciência, que são fundamentais para o professor posicionar-se de modo crítico perante a educação e a sociedade. Sinalizam, então, para que tal situação seja revertida, e que sejam feitas propostas de pesquisa em educação nesses cursos.

Com preocupação análoga, Ponte (2002b) menciona a pesquisa diagnóstica de duas educadoras matemáticas norte-americanas (Lampert \& Ball) sobre a formação inicial de professores, apontando aspectos negativos de modo geral nos modelos, algo que a literatura nacional e internacional corrobora e que está consoante aos problemas apontados anteriormente por Cunha \& Cecillini (1995) e por outros autores que discutem com mais ênfase a formação de professores em Ciências e Matemática.

Lampert \& Ball (1999 apud PONTE, 2002b) sublinham no estudo mencionado a relevância do incentivo à capacidade dos novos professores em analisar a própria prática e desenvolver hipóteses sobre ela, em colaboração com outros professores. No mesmo sentido Paiva (2002), afirma que durante o curso inicial de professores que os saberes docentes começam a ser construídos, sendo os primeiros anos de formação definitivos para que o professor em formação se constitua num profissional.

Um outro elemento que destaco é a falta de espaço e ambiente de realização da formação continuada do professor. Momentos estimuladores da reflexão sobre os problemas envolvendo sua prática são necessários e têm possibilidades de reorientação dos aspectos metodológicos da prática em Ciências e Matemática abordados ao longo do texto. Tal problema merece ser aprofundado por parte dos sujeitos que atuam no ambiente escolar, mas sobretudo, necessita ser visto pelos gestores federais, estaduais e municipais, como algo imprescindivel para uma reconfiguração das práticas escolares.

Embora os problemas apontados e as conseqüências e causas envolvidas, sejam complexos, exigindo soluções compativeis, com relações que extrapolam o âmbito estritamente pedagógico, existem movimentos de professores formadores, com grupos preocupados com a prática pedagógica nas áreas de Ciências e Matemáticas, que assumem como desafio maior a melhoria do ensino de ciências e matemática, através do incentivo a momentos de estudos que auxiliam professores a inovarem suas metodologias de ensino mediante o questionamento e análises de situações, experiências da própria prática (PONTE, 2002 a; FIORENTINI \& JIMÉNEZ, 2003). Esse potencial formativo em colaboração e reflexão será abordado mais à frente.

\section{METODOLOGIADA EDUCAÇÃO EM CIÊNCIASE MATEMÁTICA: POSSIBILIDADES POR MEIODE PROJETOS DIDÁTICOS INTERDISCIPLINARES}

No sentido de contribuir com o debate acerca dos equívocos metodológicos envolvendo as práticas dos professores na educação básica., aponto como perspectiva interventiva da metodologia de projetos (ANTUNES, 2001; HERNANDEZ \& VENTURA, 1999; NOGUEIRA, 2001). Tal proposta traz um potencial interdisciplinar, interessante $\mathrm{e}$ desafiante ao planejamento, podendo envolver o ensino de matemática (BELLO \& BASSOI, 2003), e também matemática e ciências (MANFREDO \& SANTANA, 2004), assim como poderá ter seus alcances maximizados se conjugada com o recurso de outras tendências metodológicas tais como História da Ciência/Matemática; utilização de jogos, a resolução de problemas; modelagem matemática, etnomatemática, a relação Ciência, Tecnologia e Sociedade-CTS- utilizadas nos momentos adequados, e apropriadamente, ao tema, tempo espaço para o estudo.

A utilização de projetos didáticos permite uma versatilidade de orientação ao professor, ao mesmo tempo em que garante autonomia reflexiva dos alunos no que tange à realização das atividades propostas. Contribui no processo de aprendizagem significativa, possibilitando aos sujeitos (professores e alunos) descobrirem juntos os 
conhecimentos das áreas envolvidas (Matemática, Ciências, Artes, História, etc.), desenvolvendo ambos saberes reflexivos e de pesquisa ${ }^{8}$. Nos termos de Hernandez \& Ventura (1999), a função exercida por projetos consiste em favorecer a criação de estratégias de organização dos conhecimentos escolares tendo em foco o tratamento da informação, a relação entre os diferentes conteúdos em torno de hipótesês que facilitem a construção do conhecimento, a transformação da informação procedente dos diferentés saberes disciplinares em conhecimento próprio. Nésse sentido, há ganhos, portanto, do ponto de vista de quem ensina, ou seja, do professor, quanto no que se refere àquele que aprende, o aluno.

É recomendável que o professor, para ter alcançados os objetivos de ensino pretendidos em sua ação didática organizada por projetos, realize observações e registros diversos, durante o processo. Assim, poderá sugerir, com base já nas constatações feitas, atividades e fontes de estudos para que os alunos desfrutem de aprendizagens significativas, dentro do projeto, visto que o professor age como facilitador do processo, ou seja, não é mais o [único] banco de dados, possuidor das informações e sim mais uma fonte alternativa, "e ser facilitador é exatamente auxiliar seus alunos a acessar essas fontes"(NOGUEIRA, 2001 , p. 203). Dito de outro modo, os momentos significativos de aprendizagens possiveis com projetos que buscam a interdisciplinaridade, favorecem e demandam:

...um comprometimento e um envolvimento do docente com a possibilidade de criar ambientes e/ou espaços escolares nos quais, além de se buscarem dados e informações, exista a oportunidade de se construir conhecimentos, desenvolver habilidades e, principalmente, formar cidadãos críticos com potencial de análise da sua realidade social e cultural. (BELLO \& BASSOI, 2003, p. 38)

Uma metodologia nesses termos torna-se bastante fértil, podendo dinamizar o planejamento de ensino, auxiliando no estabelecimento de objetivos, na inovação de estratégias, na realização de avaliações coerentes e eficazes, podendo nessa perspectiva lidar apropriadamente com as questões que interferem no processo de ensino e de aprendizagem de conceitos, atitudes e procedimentos ou processos nas várias áreas do conhecimento escolar (NOGUEIRA, 2001). Essas ações, na medida em que vão sendo vividas e investigadas pelo professor, possibilitam uma melhora progressiva de sua autonomia e ampliação de sua competência no ensino, o que abrirá canais de bem estar na profissão

\section{ASSUMIREAPOIARATENDÊNCIADAREFLEXÃOE DA PESQUISA: UM DESAFIO DOS ESPACOS FORMATIVOS}

É, entretanto, importante destacar que para o professor utilizar dessa inovação metodológica com propriedade, assumindo-a como uma maneira de desenvolver sua prática de ensino em Cências e Matemática, é necessário que seu pensamento esteja atinente ao que Morin (2002) refere como "reforma de pensamento", ou seja, uma cabeça voltada para o novo, aberta às mudanças, tendo como base um paradigma epistemológico que corrobora a articulação de saberes por um sujeito cognoscente que constrói e reconstrói esquemas conceituais por meio intra e intersubjetivo, numa relação dinâmica e dialógica, que assim, torna-se prenhe de possibilidades Encontra-se aí um dos muitos desafios às instâncias no que tange aos currículos dos cursos oferecidos no âmbito da formação inicial e contínua de professores que alimentam propostas reflexivas.

É com tal interesse que discuto o potencial transformador que traz as tendências formativas baseadas na reflexão e investigação sobre a prática profissional de professores, como mecanismo de formação no âmbito dos cursos assim como no seio das instâncias onde os professores atuam, sendo, nesse sentido um desafio a ser enfrentado por todos.

O paradigma do professor-pesquisador, observado na literatura disponível (PIMENTA, 1997, 1999, ALARCÃO, 2003; GARCIA, 1992; SCHON, GONÇALVES, 2000; 1992; ZEICHNER, 1992, 1993), que concebe a idéia da pesquisa da própria prática, tem suas justificativas assentadas no princípio de que os problemas apresentados na prática docente não poderão ser resolvidos mediante soluções técnicas encontradas em outras pesquisas cujos objetivos são externos aos contextos vividos, isto é, na realidade a que se aplica. Dito de outro modo, somente os sujeitos que enfrentam os problemas oriundos nos momentos das aulas, podem investigá-los e a partir da reflexão sistemática e criteriosa, encontrar soluções que podem alterar a realidade investigada.

Nesse sentido, o investimento formativo, inicial e contínuo, que se defende é que os professores tenham ou obtenham instrumentos teórico-metodológicos para agir como investigadores da própria prática pedagógica. Devem construir habilidades, destrezas necessárias ao ensino reflexivo, as quais auxiliam em atitudes reflexivas (GONÇALVES, 2003; VASCONCELOS, 2003) que o tornam capazes de compreender e agir sobre o fenômeno educativo, desenvolvendo saberes da profissionais da docência que sedimentadores da identidade docente, de ser professor (NÓVOA, 1995; PIMENTA, 1999, PAIVA, 2002). Mas para isso, é necessário que sejam definidos currículos e práticas dos formadores nas universidades e outros espaços formativos compatíveis com tal perspectiva, ou seja, "mediante estratégias e actividades que possibilitem a aquisição de um pensamento e de uma prática reflexivas (VASCONCELOS, 2003, p. 02). Faz-se necessária, portanto, que professores em formação inicial, nesse sentido, experimentem tais possibilidades teóricas e práticas desde o início de seus cursos (ALARCÃO, 2003; GONÇALVES,

\footnotetext{
${ }^{8}$ Segundo ANTUNES (2001, p. 15) "Um projeto é, em verdade, uma pesquisa ou uma investigação, mas desenvolvida em profundidade sobre um tema ou um tópico que se acredita interessante conhecer. Essa pesquisa ou investigação deve ser desenvolvida por um grupo pequeno de alunos, algumas vezes pela classe inteira e em algumas circunstâncias excepcionais pode ser desenvolvida apenas por um aluno como também por mais de uma classe ou um grupo de alunos de diferentes classes".
} 
2000; MANFREDO, 2004). Junto a isso, é fundamental que sejam criados no âmbito da própria escola espaços voltados para esse fim. Além do incentivo aos professores para que participem ativamente de cursos de formação como a pós-graduação, atualização, posto que sem esses momentos a tendência reflexiva e inovadora pela pesquisa da própria prática, terá dificuldades em tornar-se uma realidade de fato na educação brasileira.

Tornar-se-á apenas um sonho, uma incoerência em termos dos discursos governamentais, ou ainda uma prática de poucos grupos isolados, que não alcançarão um número expressivo de professores, caso não haja investimentos sérios em políticas salariais e de organização de espaço e tempo de atividades curriculares nos sistemas Municipal, Estadual e Federal de ensino das regiões no País. Tais iniciativas conjugadas na tentativa de melhoria do ensino, darão possibilidade de exercício da prática reflexiva e investigadora, que alimenta o próprio desenvolvimento profissional do professor (ALARCÃO, 2003; NÓVOA, 1992; PONTE, 2002a, 2002b, GONÇALVES, 2000; MANFREDO, 2004).

\section{CONSIDERAÇÕES FINAIS}

As questões evidenciadas como problemas que vêm caracterizando o ensino de Ciências e o ensino de Matemática ao longo da escolarização básica, assim como possibilidades e perspectivas de intervenção nessa realidade evidenciadas e discutidas neste texto, convidam a todos a pensar, de modo mais prático, nas relações existentes entre uma ação reflexiva com pesquisa implementada por professores dessas áreas e as possíveis metodologias de como torná-la possível, no âmbito da educação fundamental e média brasileira. Desafio este a ser assumido pelas instâncias que atuam na formação de professores, desde que se alinhem na luta pela democratização do ensino e por uma qualidade educacional que expresse um ensino nos termos aqui evidenciados, ou seja, na competência científica e matemática das gerações, atuais e futuras.

Nessa perspectiva, sinalizo para algumas recomendações que sintetizam formas de pensar e propor uma formação de professores de Ciências e Matemática no escopo de uma prática reflexiva aqui defendida que enfrente e supere as contradições percebidas: no âmbito dos cursos universitários de formação docente devem ser ampliadas as discussões sobre formação de professores, e com isso as relações ensino-pesquisa, na perspectiva reflexiva. Isso envolvendo tanto os professores formadores quanto os alunos-professores em formação; (2) Nos ambientes escolares onde atuam os professores, devem ser garantidos tempo, espaço e condições para que possam desenvolver estudos individuais e coletivos, com relatos e trocas de experiências sobre suas práticas; (3) Fomento e abertura de canais de intercâmbio com universidades e centros de formação para que a pesquisa no ensino possa desenvolver-se em colaboração entre professores das escolas e formadores de professores e alunos em formação na universidade; (4) No que se refere ao papel formativo via secretarias de educação (municipal e estadual), deve ser discutida uma re-orientação das propostas implementadas pelo corpo técnico (coordenadores, supervisores, orientadores, etc.), no sentido de que atendam às necessidades da prática reflexiva e investigativa dos professores, estando em sintonia com os problemas reais que estes enfrentam na prática, e nesse sentido, também, a relação com as universidades deve ser ampliada; (5) e finalmente, que haja real valorização do profissional da educação em termos tanto de incentivo (com condições) aos estudos pós-graduados, bem como no que tange um plano de carreira em que seja garantida remuneração compatível com a titulação e com o grau de importância que merece a profissão de professor.

Acredito que a desconsideração por aquilo que tais pontos sugerem, tornam inócuas ou inconsistentes quaisquer propostas lançadas no âmbito da formação de professores, de modo geral, e de professores de Ciências e Matemática, de modo particular neste País.

\section{REFERÊNCIAS BIBLIOGRÁFICAS}

ARAÚJO, C.G. \& LUZIO, N. (2004). Dificuldades do ensino de matemática. Disponível em www.inep.gov.br/imprensal artigos. Acesso em 02/12/2004.

ALARCÃO, I.(2003) Professores reflexivos em uma escola reflexiva. São Paulo, Cortez, (Questões da nossa época).

ANTUNES, C. (2001).Um método para o ensino fundamental: o projeto. Petrópolis, RJ: Vozes.

BELLO, E. L. S. \& BASSOI, S. T. (2003) A pedagogia de projetos para o ensino interdisciplinar de matemática em cursos de formação continuada de professores In: Educação Matemática em Revista- Revista da Sociedade Brasileira de Educação Matemática, Número 15, Ano 10, Dez.

CARRAHER, T. et all. (1995). Na vida dez na escola zero. São Paulo: Cortez.

CUNHA, A. M. O. \& CICILLINI, G.A.(1995). Considerações sobre o ensino de ciências para a escola fundamental. In: VEIGA, I. P. A. Escola, Curriculo e Ensino, $2^{\mathrm{a}}$ ed. Campinas, S.P: Papirus (Magistério, Formação e Trabalho docente).

DELIZOIĊOV, D. \& ANGOTT, L.(1998) Metodologia do ensino de ciências. SP: Cortez.

FIORENTINI, D. \& JIMENEZ, A.(org.). (2003). Histórias de aulas de Matemática: compartilhando saberes profissionais. Campinas, S.P, Gráf. FE: CEMPEM.

GARCÍA, C. M. A (1992).Formação de professores: novas perspectivas baseadas na investigação sobre o pensamento do professor. In: NÓVOA, A.(Org.). Os professores e a sua formação. Lisboa, Dom Quixote.

GONÇALVES, T. V.O.(2000).Ensino de Ciências e matemática e formação de professores: marcas da diferença. Campinas, SP, FE/UNICAMP. (Tese de Doutorado). 
(2003). Formação inicial de professores: prática docente e atitudes reflexivas In: Anais do ENPEC, Novembro.

HERNÁNDEZ, F. \& VENTURA, M. (1999). A organização do curriculo por projetos de trabalho: o conhecimento é um caleidoscópio. Porto Alegre: Artes Médicas.

MANFREDO, E. C. G.(2004).Inovação na Licenciatura: cartografando uma reforma curricular. Belém, PA, NPADC. (Dissertação de Mestrado).

\& SANTANA.(2004). Projetos didáticos para 0 ensino de ciências para as séries iniciais: algumas reflexões. Publicação especial da SBPC. $7^{a}$ Reunião Regional, Belém$\mathrm{Pa}(25 \mathrm{a} 28 / 08 / 04)$.

MEDEIROS, C.F. de.(1989) Por uma educação Matemática como intersubjetividade. In: BICUDO, M.A.V.(org.). Educação matemática. São Paulo: Editora Moraes.

MIRANDA, M. G. O professor pesquisador e sua pretensão de resolver a relação entre teoria e a prática na formação de professores. In: ANDRÉ, M. (org.). O papel da pesquisa na formação e na prática dos professores.Campinas, SP, Papirus, 2001.(Série prática pedagógica)

MORIN, E.(2002). Educação e complexidade: os sete saberes e outros ensaios (Maria da Conceição Almeida \& Edgar de Assis Carvalho (orgs.). São Paulo, Cortez.

MOURA, G.R.S. (2003). O ensino de ciências na $5^{\mathrm{a}}$ e na $6^{\mathrm{a}}$ séries da Escola Fundamental. In: NARDI, R.(org.). Educação em Ciências: da pesquisa à prática docente. São Paulo: Escrituras (Educação para a Ciência).

NAMERI, M. (1995). O outro lado da Matemática. In: CARDOSO, M.H.F \& VEIGA, I. P. A. Escola, Curriculo e Ensino, 2a ed. Campinas, S.P: Papirus (Magistério, Formação e Trabalho docente).:

NOGUEIRA, N. R. (2001). Pedagogia dos projetos: uma jornada interdisciplinar rumo ao desenvolvimento das múltiplas inteligências. São Paulo: Érica.

NÓVOA, A. (1995). Os professores e as histórias de sua vida. In: NÓVOA, Antônio (org.). Vidas de professores. Porto. Porto editora.

(1992).Formação de professores e profissão docente. In: NÓVOA, Antônio (org.) Os professores e a sua formação. Lisboa, D. Quixote.

PAIVA, M.A.V.(2002). Saberes do professor de Matemática: uma reflexão sobre a licenciatura. Educação Matemática em Revista. Revista da Sociedade Brasileira de Educação Matemática. Ano 9, no 11, Abril

PIMENTA,. S. G.(1999). Formação de professores: saberes e identidade da docência. In: Saberes pedagógicos e atividade docente, São Paulo, Cortez.
(1997). A didática como mediação na construção da identidade do professor - uma experiência de ensino e pesquisa na licenciatura In: ANDRÉ, M. E. D. A. \& OLIVEIRA, M. R. S.(orgs). Alternativas no ensino de didática. Campinas, SP. Papirus, 1997 (Coleção Prática Pedagógica).

PONTE, J. P. (2002a)Investigar a nossa própria prática In: GTI (Grupo de Trabalho sobre Investigação). Associação de Professores de Matemática. Refletir e investigar sobre a prática profissional. S/L.: APM.

(2002b). A vertente profissional da formação inicial de professores de matemática. Educação Matemática em Revista. Revista da Sociedade Brasileira de Educação Matemática. Ano 9, no 11, Abril.

ROCHA, I.C.B. (2001). Ensino de matemática: formação para a exclusão ou para a cidadania? Educação Matemática em Revista. Revista da Sociedade Brasileira de Educação matemática, no 9 , ano 11

SCHNETZLER, R. P.(1992). Construção do conhecimento e ensino de ciências. Em Aberto. Brasília, no 55.

SCHÖN, D.(1992). Formar professores como profissionais reflexivos In: NÓVOA, A.(org.) Os professores e a sua formação. Porto: Porto.

SILVA, J.A..M.(2002). Educação matemática e exclusão social: tratamento diferenciado para realidades desiguais. Brasilia: Plano editora.

TANCREDI et all.(2001). Os cadernos dos alunos e a aprendizagem da matemática. Educação Matemática em Revista. Revista da Sociedade Brasileira de Educação matemática, no 11 , ano 8 , dez.

TEIXEIRA, P.M.M. \& VALE, J.M.F. do.(2003). Ensino de Biologia e cidadania: problemas que envolvem a prática pedagógica de educadores. In: NARDI, R.(org.). Educação em Ciências: da pesquisa à prática docente. São Paulo: Escrituras (Educação para a Ciência).

VASCONCELOS, C. C. Os professores têm necessariamente que refletir sobre a sua prática pedagógica, pois sem isso não há mudança possível em educação. Disponível em www.ipv/millenium/17ect9.htm.

THOMAZ, T.C..F. (1994) Reflexões sobre o ensinoaprendizagem da matemática, considerando o desenvolvimento cognitivo e a classe social. In: Revista da Secretaria Municipal de educação -Prefeitura Municipal de Porto Alegre, no 07, Junho.

ZEICHNER, K. M. (1992).Novos caminhos para o practium: uma perspectiva para os anos $90 \mathrm{In}$ : NÓVOA, A.(org.). Os professores e a sua formação. Porto: Porto, 1992.

(1993). Formação reflexiva de professores: idéias e práticas. Lisboa, Educa. 